\title{
Identification of Configurational Effectiveness on Improvement of Tractor Stability on Uneven Roads
}

\section{LI, Zhen}

Beijing Key Laboratory of Optimized Design for Modern Agricultural Equipment, China Agricultural University | Laboratory of Agricultural Machinery and Production Systems Design, Division of Bi-oproduction Environmental Sciences, Department of Agro-environmental Sciences, Faculty of Agriculture, Kyushu University

\section{MITSUOKA, Muneshi}

Laboratory of Agricultural Machinery and Production Systems Design, Division of Bi-oproduction Environmental Sciences, Department of Agro-environmental Sciences, Faculty of Agriculture, Kyushu University

\section{INOUE, Eiji}

Laboratory of Agricultural Machinery and Production Systems Design, Division of Bi-oproduction Environmental Sciences, Department of Agro-environmental Sciences, Faculty of Agriculture, Kyushu University

\section{OKAYASU, Takashi}

Laboratory of Agricultural Machinery and Production Systems Design, Division of Bi-oproduction Environmental Sciences, Department of Agro-environmental Sciences, Faculty of Agriculture, Kyushu University

他

https://doi.org/10.5109/1911200

出版情報：九州大学大学院農学研究院紀要. 63 (1)，pp.113-117，2018-02-27. Faculty of Agriculture, Kyushu University バージョン :

権利関係 : 


\title{
Identification of Configurational Effectiveness on Improvement of Tractor Stability on Uneven Roads
}

\section{Zhen LI'* ${ }^{*}$, Muneshi MITSUOKA², Eiji INOUE ${ }^{2}$, Takashi OKAYASU', Yasumaru HIRAI', Zhongxiang $\mathrm{ZHU}^{1}$, Zhenghe $\mathrm{SONG}^{1}$ and Enrong $\mathrm{MAO}^{1}$}

\author{
Laboratory of Agricultural Machinery and Production Systems Design, Division of Bioproduction Envi-ronmental Sciences, \\ Department of Agro-environmental Sciences, Faculty of Agriculture, \\ Kyushu University, Fukuoka 812-8581, Japan \\ (Received October 31, 2017 and accepted November 20, 2017)
}

\begin{abstract}
It has been identified that tractor stability can be affected by multiple factors, including configurational and environmental parameters. To improve tractor stability and enhance the resistance of the tractorimplement system to exterior disturbs, three tractor physical parameters were selected as the key control factors to examine their statistical significances and to find out the corresponding desired levels. In this study, a scaled experimental system consisting of a scaled tractor-implement model, force-sensing system, random road surfaces was developed. The tractor was operated to travel forward passing over two classes of rough road. Various tractor configuration patterns were assigned following the L27 orthogonal array according to the Taguchi design of experiment. Adopting the concept of lateral-load transfer ratio, the output voltage signals of the force sensing resistors were calculated for the stability indexes basing on tractor front and rear axles. Results showed that the type of tractor front tire and the ballast weight significantly varied the ground contact condition of the front tires, while the rear track width of the tractor predominantly determined the rear-axle-based vehicle stability.
\end{abstract}

Key words: Scale Model Tractor, Lateral Stability, Experimental System, Taguchi Method

\section{INTRODUCTION}

Tractor rollover has been seriously threatening the lives of operators for decades, without restriction to any certain countries or regions. Worldwide, rollover accidents averagely account for over half of the tractorrelated deaths (Abubakar et al., 2010). From a passive perspective, rollover protective structure (ROPS) has been developed and equipped by most tractors, it greatly helps protect drivers inside the operation space together with the use of safety belt. On the other hand, efforts have been made to find out the mechanism of a tractor rollover process. Some studies tried to predict tractor behaviors through static, quasi-static, or dynamic mathematical models (Homori et al., 2003; Takeda et al., 2010; Guzzomi, 2012; Smith et al., 1974; Li et al., 2014a, 2014b, 2015; Li et al., 2015a, 2015b). With certain unlockable restrictions of these models, however, it is difficult to verify considerable tractor conditions in practical agricultural fields.

Experimental approach provides a more realistic way for direct and accurate response observation of tractors. Considering that the experiments involving tractors in real scale are significantly dangerous and costly, it is therefore necessary and more efficient to develop the scaled experimental platform for investigations on tractor rollovers (Davis and Rehkugler, 1974; Yang et al.,

${ }^{1}$ Beijing Key Laboratory of Optimized Design for Modern Agricultural Equipment, China Agricultural University, China

${ }^{2}$ Laboratory of Agricultural Machinery and Production Systems Design, Division of Bi-oproduction Environmental Sciences, Department of Agro-environmental Sciences, Faculty of Agriculture, Kyushu University, Japan

* Corresponding author (E-mail: zhenli@cau.edu.cn)
1991). A recent study reveals that several tractor physical parameters, such as tractor tire, track width, implement height, and ballast weight, play key roles in changing tractor stability (Abu-Hamdeh and Al-Jalil, 2004; Crolla and Horton, 1984; Previati et al., 2014; Li et al., 2016). It still remains uncertain that to what extent the most influential parameters are statistical significant, or if they remain the significance in all conditions.

This study aimed to investigate the effects of three most influential factors and their interactions on tractor stability on a scaled experimental platform. The experimental system was expected to be composed of a scale model tractor, road tracks in random profiles, and force sensing subsystem. The expected results should clearly explain the relative significance of the selected factors for tractors on uneven roads in different roughness levels.

\section{MATERIALS AND METHODS}

This study employed a scale-model-based approach to assess tractor lateral stability on slopes. The scale model system was mainly developed for measurement of the dynamic reaction forces applied to tractor tires, which consists of a scale model tractor, the uneven road surface segments, the force sensors, and the data logger, as Fig. 1 illustrates. In accordance with the active sensing area of the Force Sensing Resistor (FSR) 408, the surface baseboards were attached with 5-mm wooden cubes on the bottom surfaces. The eight cubic blocks on each base board were arranged in two lines and isometrically spaced. Sticking the bottom surfaces of the wooden cubes to the FSR devices eventually gave supportive track segments (the four surface-board-FSR sets) and stable outputs. The random surfaces painted in gray 


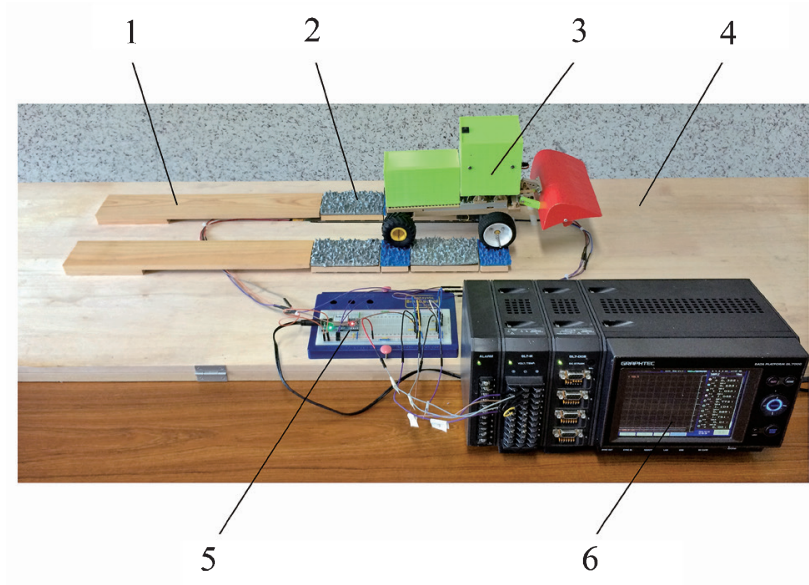

Fig. 1. Experimental setup of the scaled force measuring system: 1. travelling track; 2 . random road surface; 3 . scale model tractor; 4. main baseboard; 5 . circuit board; 6 . data recorder.

color represent the effective measuring area while the scale model tractor travels forward. To give the model tractor a practical state of vibration before the measurement starts, four pieces of random surfaces in blue color having the same degree of road roughness were set as the pre-run roads to oscillate pre-vibration for the tractor.

As shown in Fig. 2, the FSR 408 sensors, two as a set, were parallelly placed on the surface of the main baseboard. Two sensor sets were used for the force variation measurement on one side of the tractor. For instance, sensor set 1 measures the dynamic ground reaction force applied to the downhill front tire of the tractor, while sensor set 4 records data for the downhill rear tire. Therefore, sensor sets $1-4$ reflect the dynamic reaction force variation of all tires in real time.

The circuit design of the force measuring system is shown in Fig. 3. There are eight accesses in total with independent signal output for each channel. The electronic units mainly used in this study are FSR variable resistor, fixed resistor, and operational amplifier. The summed output voltage of two neighbor channels eventually gives the converted force value for one tractor tire.

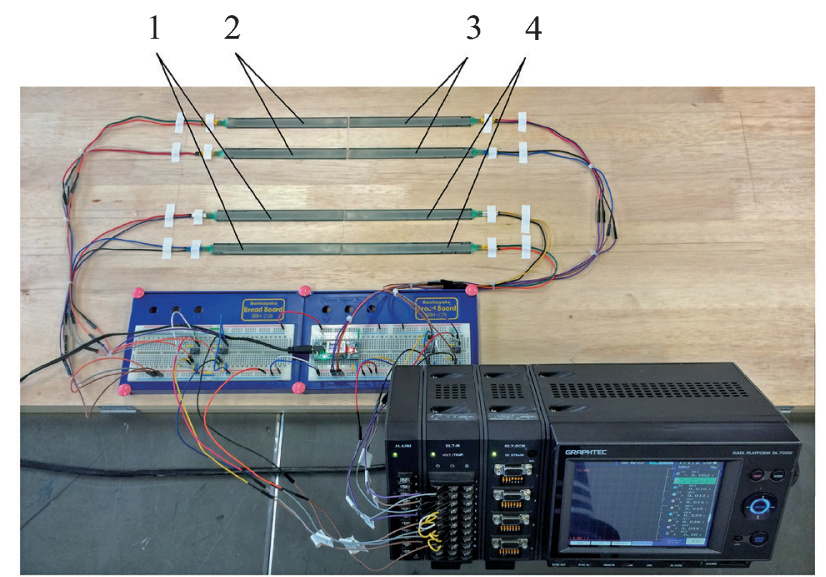

Fig. 2. Configuration of the tire-ground force sensing system.

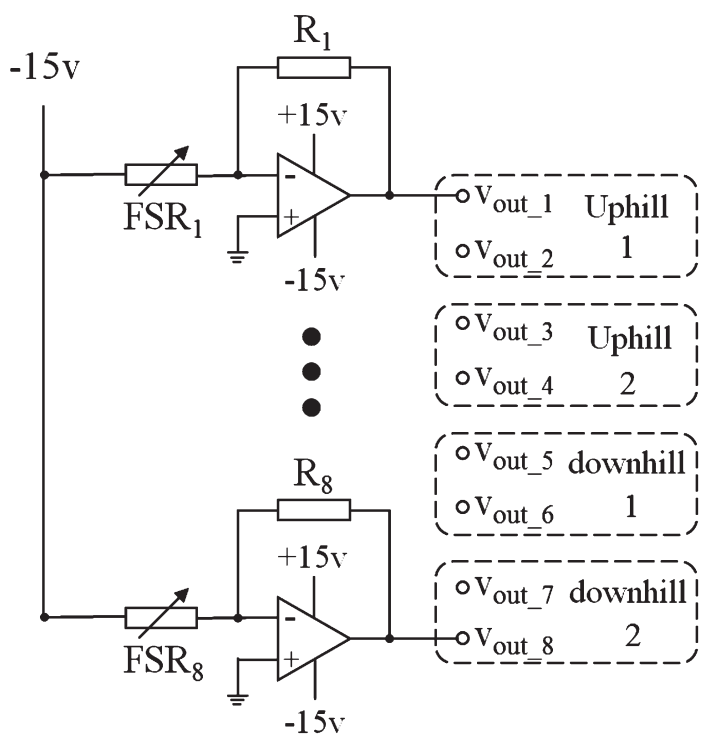

Fig. 3. Scheme of the circuit design.

Regarding the fact that the practical fields and roads where tractors are operated are commonly uneven without designated profiles, it is therefore necessary to consider tractor travelling tracks with random surfaces in the scaled experimental system. According to ISO 8608 (2016), practical random terrains can be classified into 8 categories A-H by their power spectral density ranges. The category of terrain correspondingly reflects the degree of road roughness, with class A representing the flattest roads and class $\mathrm{H}$ representing the most uneven terrains. As has been identified by previous studies (Torisu et al., 1979; Matthews, 1966), road classes E and $\mathrm{F}$ have been found the most typical road roughness levels regarding the agricultural fields that tractors are operated. Following the instruction of ISO 8608 (2016), we programed with MATLAB to create the virtual scale road surface profiles for road classes $\mathrm{E}$ and $\mathrm{F}$. Transferring the coordinate information of the random roads into the software Rhinoceros enabled the road reconstruction in a three-dimensionally printable form. By exporting the file in suitable data format to the $3 \mathrm{D}$ printer Cubex Duo, the generated virtual road segments can be manufactured piece by piece, as shown in Fig. 4 .

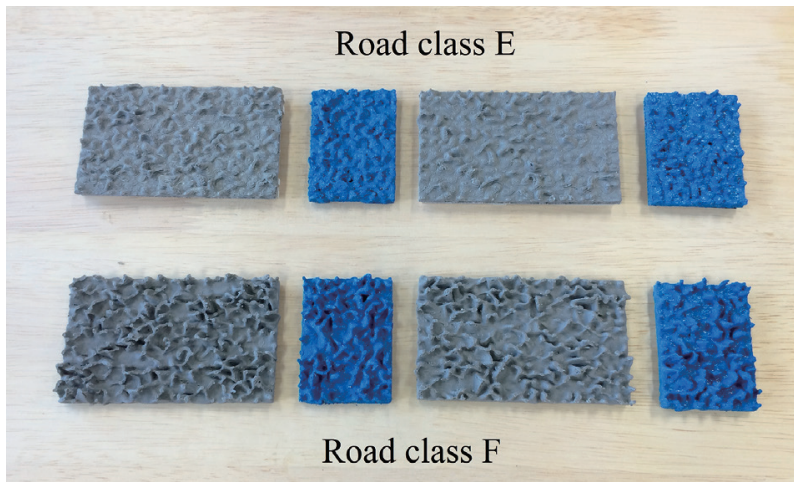

Fig. 4. Random road surfaces in roughness classes $\mathrm{E}$ and $\mathrm{F}$ produced by 3D printer. 
To evaluate tractor stability, the indexes basing on the lateral load transfer ratio (LTR) were adopted. In this study, we defined two types of LTR indexes for the front and rear axles to separately track the factorial effects on varying tractor front/rear-tire-based ground contact condition, which were defined as follows:

$$
\begin{aligned}
& L T R_{f}=\frac{F_{f_{-} \text {down }}-F_{f_{-} u p}}{F_{f_{-} \text {down }}+F_{f_{-} u p}} \\
& L T R_{r}=\frac{F_{r_{-} \text {down }}-F_{r_{-} u p}}{F_{r_{-} \text {down }+} F_{r_{-} u p}}
\end{aligned}
$$

where $L T R_{f}$ is the front-axle-based tractor stability index; $L T R_{r}$ is the rear-axle-based tractor stability index; $F_{f \text { down }}$ is the ground reaction force applied to the downhill front tire of the tractor, $\mathrm{N} ; F_{\text {f up }}$ is the ground reaction force applied to the uphill front tire of the tractor, $\mathrm{N} ; F_{r_{-} \text {down }}$ is the ground reaction force applied to the downhill rear tire of the tractor, $\mathrm{N} ; F_{r_{-} \text {up }}$ is the ground reaction force applied to the uphill rear tire of the tractor, $\mathrm{N}$.

Employing the Taguchi method to find out the effects of the most influential factors on improving tractor stability among the factors studied by Li et al. (2016), tractor front tire (factor 1), ballast weight (factor 2), rear track width $\left(w_{r}\right.$, factor 3$)$, and their interactions were selected as the control factors, while road roughness was considered the only noise factor. Table 1 gives the L27-orthogonal-array-based experimental arrangement including the factors and their levels.

\section{RESULTS AND DISCUSSION}

At a forward speed of $0.2 \mathrm{~m} / \mathrm{s}$, the scale model tractor was operated on a fixed lateral incline of 10 degrees. Following the pattern showed in Table 1, 27 experimental runs under each road roughness condition of classes $\mathrm{E}$ and $\mathrm{F}$ were performed. Fig. 5 shows the main effects of the three factors and their interactions on the frontaxle-based tractor stability index $L T R_{f}$. In Fig. 5(a), it is clear that factor 2 (frontal ballast weight) owns the predominant significance among the three main factors on $L T R_{f}$, followed by Factor 1 (front tire). On the other hand, factor 3 (rear track width, $w_{r}$ ) presents negligible
Table 1. The Taguchi design of experiment using the L27-

\begin{tabular}{|c|c|c|c|}
\hline No. & Factor 1 & Factor $2(\mathrm{~g})$ & Factor $3(\mathrm{~cm})$ \\
\hline 1 & $\mathrm{~A}$ & 0 & 10 \\
\hline 2 & $\mathrm{~A}$ & 0 & 13 \\
\hline 3 & A & 0 & 16 \\
\hline 4 & A & 80 & 10 \\
\hline 5 & A & 80 & 13 \\
\hline 6 & A & 80 & 16 \\
\hline 7 & A & 160 & 10 \\
\hline 8 & A & 160 & 13 \\
\hline 9 & A & 160 & 16 \\
\hline 10 & B & 0 & 10 \\
\hline 11 & B & 0 & 13 \\
\hline 12 & B & 0 & 16 \\
\hline 13 & B & 80 & 10 \\
\hline 14 & B & 80 & 13 \\
\hline 15 & B & 80 & 16 \\
\hline 16 & B & 160 & 10 \\
\hline 17 & B & 160 & 13 \\
\hline 18 & B & 160 & 16 \\
\hline 19 & $\mathrm{C}$ & 0 & 10 \\
\hline 20 & $\mathrm{C}$ & 0 & 13 \\
\hline 21 & $\mathrm{C}$ & 0 & 16 \\
\hline 22 & $\mathrm{C}$ & 80 & 10 \\
\hline 23 & $\mathrm{C}$ & 80 & 13 \\
\hline 24 & $\mathrm{C}$ & 80 & 16 \\
\hline 25 & $\mathrm{C}$ & 160 & 10 \\
\hline 26 & $\mathrm{C}$ & 160 & 13 \\
\hline 27 & C & 160 & 16 \\
\hline
\end{tabular}
orthogonal-array

effect on varying $L T R_{f}$. Specifically, it followed a theheavier-the-better principle regarding the factor of frontal ballast weight. For the front tire B of factor 1, representing a kind of tractor tires with low stiffness, was found to have positive result in promoting tractor lateral stability, while the diameter of tractor front tires did not show such effect that much. Furthermore, as can be seen in Fig. 5(b), the results of the interactions among the three factors showed nearly parallel line segments,
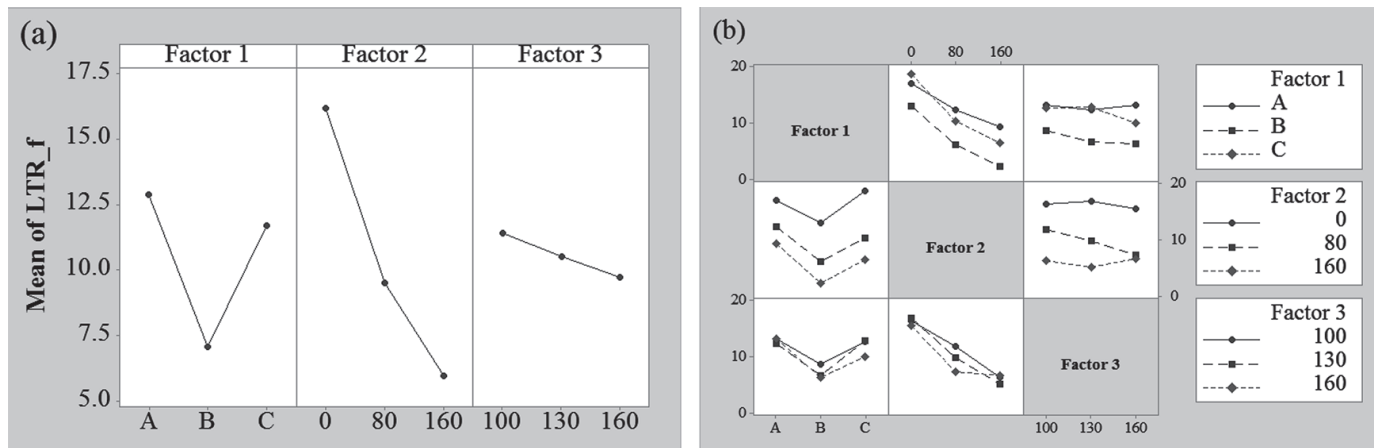

Fig. 5. Main effects of the factors on $L T R_{f}$ (a) plot for the control factors; (b) plot for the factorial interactions. 
indicating the inexistence of factorial interacting phenomena.

The effects of the main factors and interactions on LTRr is illustrated in Fig. 6. Unlike the results for $L T R_{f}$, factors 1 and 2 showed negligible effects when considering the ground forces applied to the rear tires. On contrast, the rear track width appeared to significantly improve tractor stability with higher values. As for the factorial interactions, there were no obvious interactive results presented since no absolute crossing lines were found. Therefore factor 3 is the only element that influences $L T R_{r}$ to a great extent.

Fig. 7 gives the results of the statistical analysis for $L T R_{f}$. Apparently, the significance of factor 1 on tractor stability increased a lot on the rougher road surface. The same tendency was followed by the main effects for SN ratios of factor 2 , while the main effects for means of factor 2 remained consistently important under both road conditions in roughness classes $\mathrm{E}$ and $\mathrm{F}$. Factor 3 and all the mutual interactions among three factors were found not to affect $L T R_{f}$ with their statistical significance levels over 0.01 .

Further results of $L T R_{r}$ were analyzed and given in Fig. 8. Under both road conditions considered in this study, factor 3 showed its statistical significance on vehicle stability for main effects of means and SN ratios. The other factors and interactions did not show apparent influence in changing $L T R_{r}$. It should be noted that for the interaction between factors 1 and 3 on road class $\mathrm{F}$, the significance increased dramatically compared with road class E. However, it still did not reach the level to be judged as statistically significant with values over 0.01 .
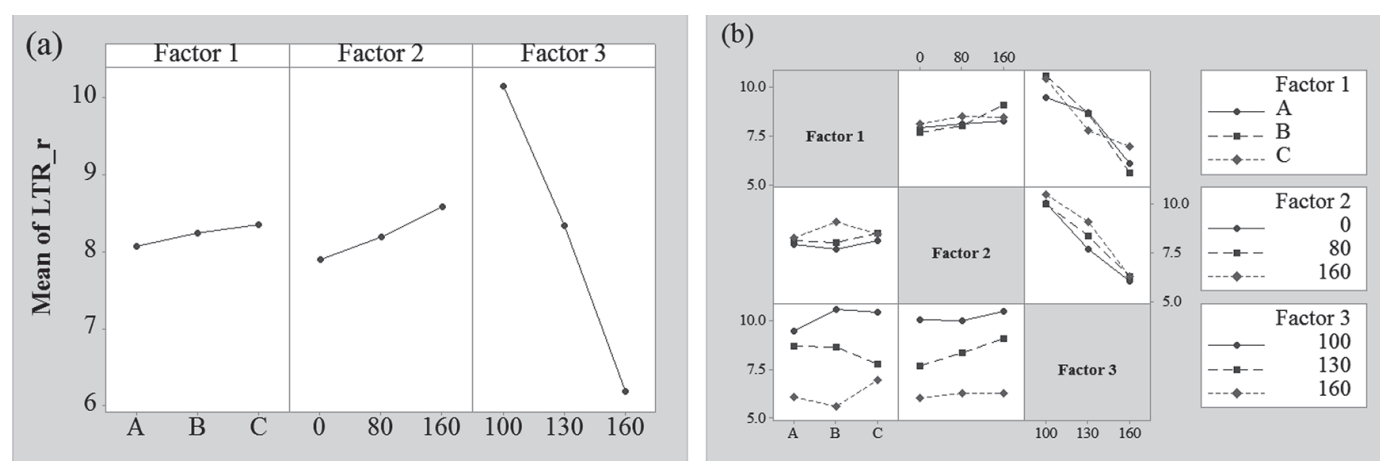

Fig. 6. Main effects of the factors on $L T R_{r}$ : (a) plot for the control factors; (b) plot for the factorial interactions.
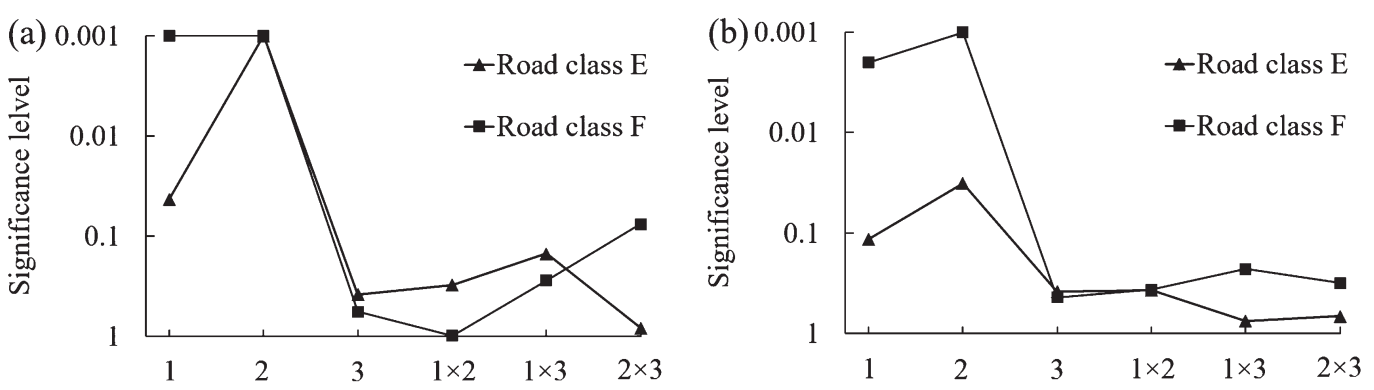

Fig. 7. Statistical significance of the factors and interactions on $L T R_{f}$ : (a) results referring to means; (b) results referring to SN ratios.
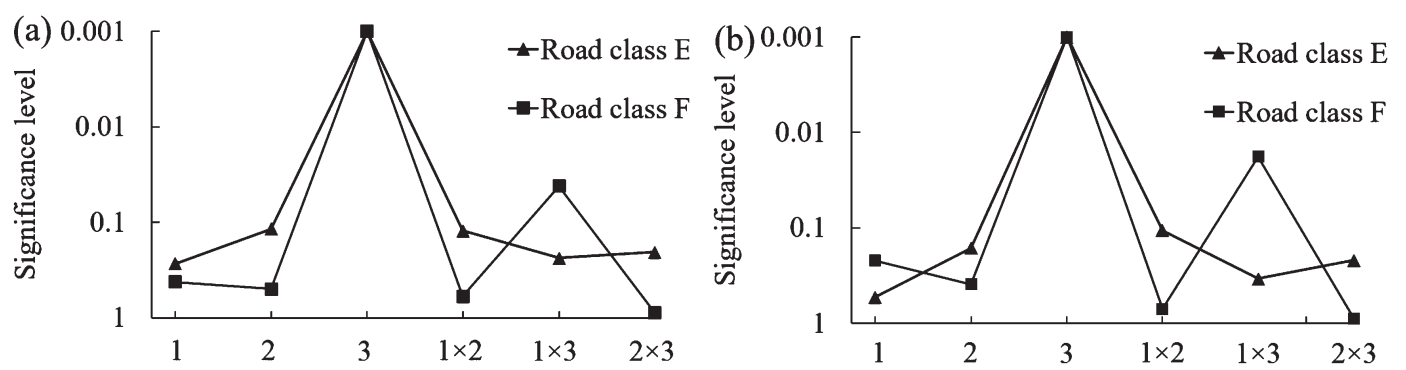

Fig. 8. Statistical significance of the factors and interactions on $L T R_{r}$ : (a) results referring to means; (b) results referring to $\mathrm{SN}$ ratios. 


\section{CONCLUSIONS}

To investigate the significance of three key physical parameters of a tractor: front tire, ballast weight, and rear track width on tractor stability, a scaled experimental system was developed in this study. The system consists of a 2 WD scale model tractor mounted with implement, travelling tracks, force sensing sets, and data recorder. As practical agricultural fields have features of unpredictable profiles, we introduced random road surfaces following ISO 8608 (2016), for the model tractor to travel over. The surface profiles of road roughness classes $\mathrm{E}$ and $\mathrm{F}$ were programed to generate the three-dimensional coordinates. After the reconstruction of the point cloud, the solid road segments were created by a 3D printer. Employing the Taguchi method, the model tractor was operated to travel forward to pass through two types of rough roads on a 10-degree lateral incline. The sensors set under the random road surfaces output voltage signals recording the contact condition between the ground and tractor tires. Tractor dynamic stability was then evaluated by the force-based indexes, including the frontaxle-based stability index $L T R_{f}$ and the rear-axle-based index $L T R_{r}$.

By analyzing the result data of the L27 orthogonal array, the main effects of the three factors and their interactions on tractor stability were given. It showed that tractor front tire and ballast weight played key roles in changing tractor stability. In specific, the trend indicated that a pair of front tires with relatively low stiffness could help improve tractor lateral stability to some extent, compared with high-stiffness-tires. The factor of tractor frontal ballast was found to follow the heavierthe-better principle. Furthermore, tractor rear track width was found to greatly improve vehicle stability in wider widths. This study provided a potential approach for qualitative examination of factorial significance of the targeted configurational parameters on tractor lateral stability. However, insight investigations into precise prediction and control of parameter values for the improvement of tractor stability are of significant necessity to be conducted in the future.

\section{AUTHOR CONTRIBUTIONS}

Z. Li designed the study, analyzed the data and wrote the paper. T. Okayasu and Y. Hirai participated in the design of the study and performed the experiments. E. Inoue and M. Mitsuoka designed the study, supervised the work and provided facilities and resources. Z. Zhu, Z. Song and E. Mao performed the statistical analysis. All authors assisted in editing of the manuscript and approved the final version.

\section{ACKNOWLEDGEMENTS}

The authors acknowledge the financial support from the Fundamental Research Funds for the Central Universities of China (No. 2017QC191).

\section{REFERENCES}

Abubakar, M. S., Ahmad, D. and Akande, F. B. 2010 A review of farm tractor overturning accidents and safety. Pertanika Journal of Science and Technology, 18(2): 377-385

Abu-Hamdeh, N. H. and Al-Jalil, H. F. 2004 Computer simulation of stability and control of tractor-trailed implement combinations under different operating conditions. Bragantia, 63(1): $149-162$

Crolla, D. A. and Horton, D. N. L. 1984 Factors affecting the dynamic behaviour of higher speed agricultural vehicles. Journal of Agricultural Engineering Research, 30: 277-288

Davis, D. C. and Rehkugler, G. E. 1974 Agricultural wheel-tractor overturns (part 2). Transactions of the ASAE, 17(3): 484-488

Guzzomi, A. L. 2012 A revised kineto-static model for Phase I tractor rollover. Biosystems Eng., 113(1): 65-75

Homori, H., Sakai, K., Sasao, A. and Sibusawa, S. 2003 2D dynamics simulator for impact oscillators analysis of tractor-implement system. Journal of the Japanese Society of Agri-cultural Machinery, $\mathbf{6 5}(1)$ : 85-90

International Organization for Standardization. 2016 ISO 8608: Mechanical vibration - Road surface profiles - Reporting of measured data. Genève, Switzerland: International Organ-ization for Standardization

Li, Z., Mitsuoka, M., Inoue, E., Okayasu, T. and Hirai, Y. 2014a Dynamic analysis of ag-ricultural wheel tractor driving on uneven surface under the influences of speed and slope angle. $J$. Fac. Agr., Kyushu Univ., 59(2): 339-343

Li, Z., Mitsuoka, M., Inoue, E., Okayasu, T. and Hirai, Y. 2014b Lateral slope effect on tipping behavior of a tractor encountering an obstacle (model development). J. Fac. Agr., Kyushu Univ., 59(2): 345-349

Li, Z., Mitsuoka, M., Inoue, E., Okayasu, T. and Hirai, Y. 2015 Development of stability indicators for dynamic Phase I overturn of conventional farm tractors with front axle pivot. Biosystems Engineering., 134: 55-67

Li, Z., Mitsuoka, M., Inoue, E., Okayasu, T., Hirai, Y. and Zhu Z. 2015a Prediction of tractor sideslipping behavior using a quasi-static model. J. Fac. Agr., Kyushu Univ., 60(1): 215-218

Li, Z., Mitsuoka, M., Inoue, E., Okayasu, T., Hirai, Y. and Zhu Z. $2015 \mathrm{~b}$ Modification of a tractor dynamic model considering the rotatable front end. J. Fac. Agr., Kyushu Univ., 60(1): 219-224

Li, Z., Mitsuoka, M., Inoue, E., Okayasu, T., Hirai, Y. and Zhu, Z. 2016 Parameter sensitivity for tractor lateral stability against Phase I overturn on random road surfaces. Biosystems Engineering., 150: 10-23

Matthews, J. 1966 Ride comfort for tractor operators. Journal of Agricultural Engineering Research, 11(1): 44-57

Previati, G., Gobbi, M. and Mastinu, G. 2014 Mathematical models for farm tractor rollover prediction. International Journal of Vehicle Design, 64(2/3/4): 280-303

Smith, D. W., Perumpral, J. V. and Liljedahl, J. B. 1974 The kinematics of tractor sideways overturning. Trans. ASAE, 17(1): 1-3

Takeda, J., Shimada M., Kikuchi Y., Nakano M., Okada S., Hiroma T. and Torisu R. 2010 Dynamic behaviors of farm tractor passing over an obstacle (part 1). Journal of the Japanese Society of Agricultural Machinery, 72(5): 464-470

Torisu, R., Matsuo, M. and Morishima, S. 1979 Characteristics of the agricultural surface undulations as origins of farm tractor vibrations. Science Bulletin of the Faculty of Agriculture, Kyushu University, 34(1-2): 7-17

Yang, J. H., Sakai, H. and Murayama, S. 1991 Side over-turning of articulated-frame skidder running along a contour line. Journal of the Japanese Forestry Society, 73(1): 1-10 